\title{
Study of Optimization based on the Motor Power and the Auxiliary Power system of the Pumped Storage Power Station
}

\author{
ZHANG Caijun ${ }^{1, a}, \mathrm{HE} \mathrm{Le}^{2, \mathrm{~b}}$ and HE Li $\mathrm{i}^{3, \mathrm{c}}$ \\ ${ }^{1}$ Hubei Bailianhe Pumped Storage Co., Ltd., Huanggang, 438600, China \\ ${ }^{2}$ School of Electrical Engineering Wuhan University, Wuhan, 430072, China \\ ${ }^{3}$ Hubei Electric Power Company Technical Training Center, Wuhan, 430072, China \\ aBLHZCJ@sina.com, bhele@whu.edu.cn, ${ }^{\mathrm{C}} 1528859432 @ q q . c o m$
}

\begin{abstract}
Keywords: Pumped Storage Power Station; Unit Start; The Auxiliary Power System; Power Optimization.
\end{abstract}

Abstract. In recent years, pumped storage power station with its unique static and dynamic benefits has been vigorously developed. But throughout the current set and operating experience of the Pumped Storage Power Station in our country, there are always some faults happens in the auxiliary power system when starting and running the motor. In order to guarantee the safe and reliable running of power system, many stations choose to lower the rate of running motor. Therefore, this paper will study the targeted optimization based on the auxiliary power system of some Plant, and give the program of power configuration, the optimization of the starting sequence of unit. Then we will give the targeted optimization mathematical model which can be generally applied.

\section{Introduction}

In the trend of developing great grid and large plant unit in our country, Pumped Storage Power Station has played an important role in maintaining the stability of power system depending on its unique features [1]. The Pumped Storage Power Station we study is a pure pumped storage power station which is regulated daily. It is equipped with 4 Reversible Unit, each has the capacity of 300MW. The Pumped Storage Power Station play an important role of peaking bear, valley filling, frequency modulation, phase modulation, emergency reserve and black start in Central China Power Grid [2]. In actual operation, there are some problems such as power irrational allocation, lower power quality and larger harmonic risks. For security reasons, power plant operation rate is relatively lower, which is not conducive to long-term healthy development of power plant [3].

With the scheme to formulate scientific and rational program to start the units, we will fully improve the starting performance of the unit. And with the scheme to optimize the auxiliary power system, we will improve the operating characteristics of the auxiliary power system, which will provide a reliable guarantee for the stable and reliable operation of the Pumped Storage Power Station. It is highly meaningful to carry on related research.

\section{Fault Analysis of the Station}

As shown in Figure 1, it is power wiring diagram of the pumped storage power station we study. From Figure1, we will find that, SFC (static frequency converter) gets its drag power supply from the first and fourth main transformer, and the auxiliary power system gets its power supply from the first and fourth main transformer or the second and third main transformer. There are three sections of auxiliary power bus, bus I and bus II are the main bus, and bus III is the alternate bus.

According to the actual operation of the auxiliary power system, SFC get its drag power supply from the first transformer, if the auxiliary power system get its power supply from the first and fourth main transformer at this time, the auxiliary power system will alarm which may affect the normal start of the unit. According to field research and simulation results analysis, it is the SFC harmonics that invades the auxiliary power system, causing the auxiliary power system harmonics content seriously overweight and then alarm. As show in Figure 1, we will obviously find that, the SFC equipment and 
the auxiliary power system connect without any reactor or filtering equipment. And SFC harmonics may easily invade the auxiliary power system, affecting the stability of the auxiliary power system.

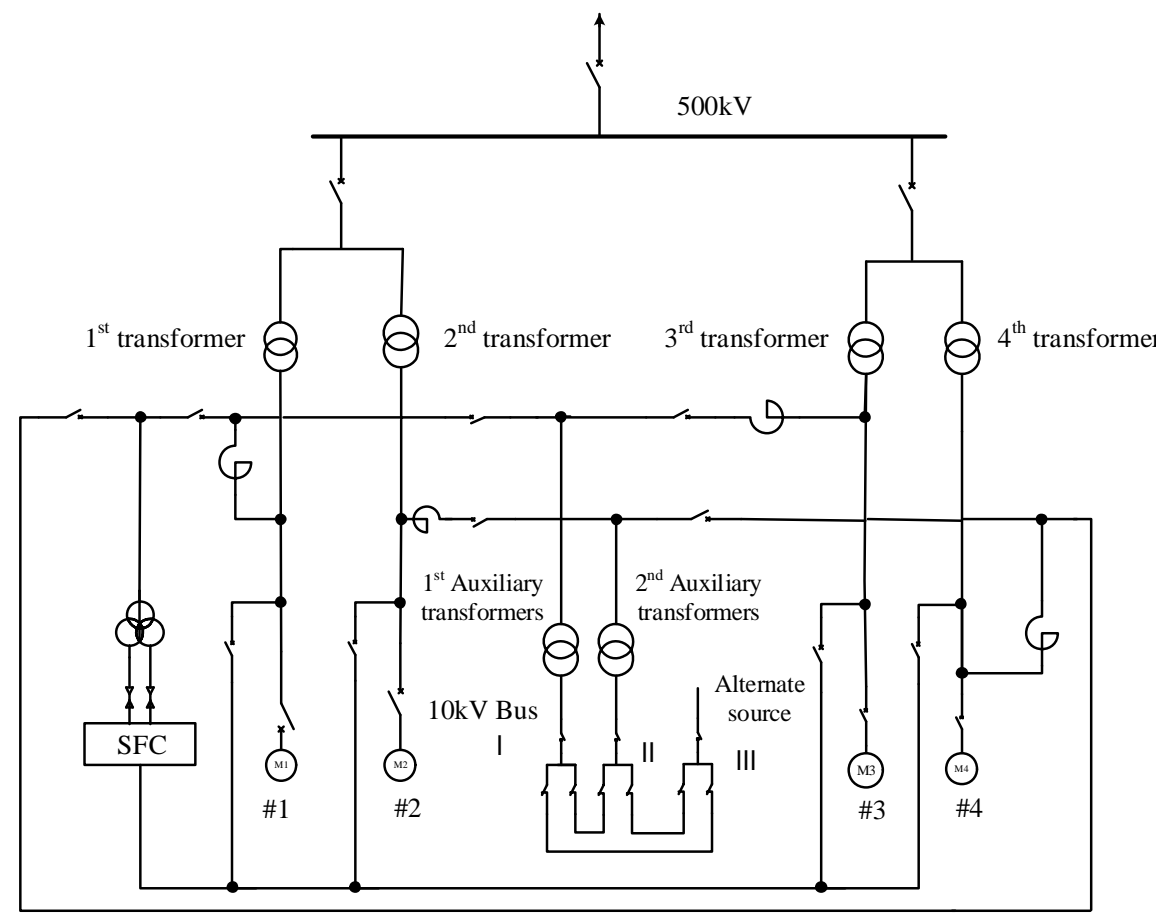

Figure1. Power wiring diagram of some pumped storage power station

Therefore, this paper gives the optimization based on the motor power and the auxiliary power system, which includes the optimization of the auxiliary power supply configuration, the optimization of starting sequence of unit and the optimization of the scheme of the auxiliary power system operation.

\section{Optimization of the Auxiliary Power Supply Configuration}

As shown in Figure 1, SFC gets its drag power supply from the first and fourth main transformer, and the auxiliary power system gets its power supply from the first and fourth main transformer or the second and third main transformer. As there is no essential difference between SFC getting its drag power supply from the $1^{\text {st }}$ and the $4^{\text {th }}$ main transformer, the SFC equipment is considered to get its drag power supply from the $1^{\text {st }}$ main transformer when designing the simulation model in this paper.

(1) The auxiliary power system gets its power supply from the $1^{\text {st }}$ and $4^{\text {th }}$ main transformer

If we start the unit when SFC equipment gets its power supply from the $1^{\text {st }}$ main transformer and the auxiliary power system gets its power supply from the $1^{\text {st }}$ and $4^{\text {th }}$ main transformer, we will get the waveform that the RMS voltage of the bus I varies with time. There is obvious voltage drop in the bus I after we start the unit, and average voltage drop is $2.6 \%$, the largest voltage drop is $5.3 \%$. And before we start the unit, THD of the voltage of bus I is about $0.76 \%$, which is far less than the national standard. During the process of starting the unit, average THD of voltage is $4.87 \%$, and the largest THD of voltage even reaches $8.25 \%$, which is significantly exceeded the industry standards.

(2) The auxiliary power system gets its power supply from the $2^{\text {nd }}$ and $3^{\text {rd }}$ main transformer

If we the unit when SFC equipment gets its power supply from the $1^{\text {st }}$ main transformer and the auxiliary power system gets its power supply from the $2^{\text {nd }}$ and $3^{\text {rd }}$ main transformer, we will get the waveform that the RMS voltage of the bus I varies with time. The RMS voltage of the bus I varies smooth, except for the moment we start the unit, there is no obvious voltage drop during the process of starting the unit. 
Then we measure the THD of voltage of bus I during the process of starting the unit. The THD of voltage of the auxiliary power system remains at around $0.8 \%$ when the auxiliary power system gets its power supply from the $2^{\text {nd }}$ and $3^{\text {rd }}$ main transformer. Obviously, it is in line with national standards.

By comparing the voltage drop and THD of bus I when the auxiliary power system gets its power supply from the $1^{\text {st }}$ and $4^{\text {th }}$ main transformer or the $2^{\text {nd }}$ and $3^{\text {rd }}$ main transformer, we will find that, when the auxiliary power system gets its power supply from the $2^{\text {nd }}$ and $3^{\text {rd }}$ main transformer, SFC harmonics have a smaller impact on the auxiliary power system. Therefore, in actual operation, the SFC equipment and the auxiliary power system should be avoided to get their power supply from the same main transformer.

\section{Optimization of Starting Sequence of Unit}

From the analyzing result foregoing, we can find that when SFC equipment gets its power supply from the $1^{\text {st }}$ main transformer, there are serious harmonic problems only when the auxiliary power system gets its power supply from the $1^{\text {st }}$ and $4^{\text {th }}$ main transformer. So we study the optimization of starting sequence of unit when SFC equipment gets its power supply from $1^{\text {st }}$ main transformer and the auxiliary power system gets its power supply from the $1^{\text {st }}$ and $4^{\text {th }}$ main transformer.

(1)Simulation analysis for the optimization of starting sequence of unit

To enable a comprehensive analysis of THD of voltage and voltage drop of the auxiliary power system, we establish an optimized assessment program for the simulation results first.

THD of the auxiliary bus is set to $\mathrm{S}$, then we can get formula (1).

$$
S\left(\left.x_{i}\right|_{i=1,2,3,4}\right)=\frac{1}{2}\left(\overline{S_{1}}\left(\left.x_{i}\right|_{i=1,2,3,4}\right)+\overline{S_{2}}\left(\left.x_{i}\right|_{i=1,2,3,4}\right)\right)
$$

$\overline{S_{1}}\left(\left.x_{i}\right|_{i=1,2,3,4}\right)$ represent for the average THD of voltage of the bus I in some starting sequence of unit, $\overline{S_{2}}\left(\left.x_{i}\right|_{i=1,2,3,4}\right)$ represent for the average THD of voltage of the bus II in some starting sequence of unit. We take $S\left(\left.x_{i}\right|_{i=1,2,3,4}\right.$ ( the average THD of the two auxiliary bus ) for the harmonic evaluation index.

Voltage drop of the auxiliary bus is set to R, then we can get formula (2).

$$
R\left(\left.x_{i}\right|_{i=1,2,3,4}\right)=\frac{1}{2}\left(\overline{R_{1}}\left(\left.x_{i}\right|_{i=1,2,3,4}\right)+\overline{R_{2}}\left(\left.x_{i}\right|_{i=1,2,3,4}\right)\right)
$$

$\bar{R}_{1}\left(\left.x_{i}\right|_{i=1,2,3,4}\right)$ represent for the average voltage drop of the bus I in some starting sequence of unit, $\bar{R}_{2}\left(\left.x_{i}\right|_{i=1,2,3,4}\right)$ represent for the average voltage drop of the bus II in some starting sequence of unit. We take $R\left(\left.x_{i}\right|_{i=1,2,3,4}\right)$ ( the average voltage drop of the two auxiliary bus ) for the voltage drop index.

And we set the comprehensive evaluation index for the optimization of starting sequence of unit to be $f\left(\left.x_{i}\right|_{i=1,2,3,4}\right)$, then we get the mathematical model of comprehensive evaluation.

$$
f\left(\left.x_{i}\right|_{i=1,2,3,4}\right)=p S\left(\left.x_{i}\right|_{i=1,2,3,4}\right)+q R\left(\left.x_{i}\right|_{i=1,2,3,4}\right)
$$

$p$ represents for the weights of harmonic evaluation index, and $q$ represents for the weights of voltage drop index, which reflects the degree of sensitivity of the comprehensive assessment index to harmonic and voltage drop. According to field research data and simulation results analysis, the main problems existed in the auxiliary power system is the seriously overweight harmonics. So when designing the value of $p$ and $q$, we design $p>q$. Here in this paper, when computing the comprehensive assessment index based on the simulation result, we can set $p=0.6, q=0.4$. So we can make it clear that the smaller $f\left(\left.x_{i}\right|_{i=1,2,3,4}\right)$ is, the optical starting sequence of unit it is.

According to the simulation result, we can compute the comprehensive assessment index in different starting sequence of unit shown in table 1.

From the simulation and computing results in table 1, we can figure it out that, if unit \#1 is started the first, the comprehensive assessment index is the largest, if unit \#1 is started the last, the comprehensive assessment index is the smallest. Therefore, in order to get the optical starting sequence, unit \#1 should be started last. 
Table 1. Value of the comprehensive assessment index in different starting sequence

\begin{tabular}{cc|cc}
\hline $\begin{array}{c}\text { Starting sequence } \\
\text { of unit }\end{array}$ & $\begin{array}{c}\text { Assessment } \\
\text { index }\end{array}$ & $\begin{array}{c}\text { Starting sequence } \\
\text { of unit }\end{array}$ & $\begin{array}{c}\text { Assessment } \\
\text { index }\end{array}$ \\
\hline (1) (2) (3) (4) & 2.79 & (3) (1) (2) (4) & 2.58 \\
(1) (2) (4) (3) & 2.79 & (3) (1) (4) (2) & 2.57 \\
(1) (3) (2) (4) & 2.77 & (3) (2) (1) (4) & 2.32 \\
(1) (3) (4) (2) & 2.76 & (3) (2) (4) (1) & 2.07 \\
(1) (4) (2) (3) & 2.79 & (3) (4) (1) (2) & 2.33 \\
(1) (4) (3) (2) & 2.92 & (3) (4) (2) (1) & 2.09 \\
(2) (1) (3) (4) & 2.54 & (4) (1) (2) (3) & 2.54 \\
(2) (1) (4) (3) & 2.55 & (4) (1) (3) (2) & 2.56 \\
(2) (3) (1) (4) & 2.32 & (4) (2) (1) (3) & 2.32 \\
(2) (3) (4) (1) & 2.08 & (4) (2) (3) (1) & 2.08 \\
(2) (4) (1) (3) & 2.31 & (4) (3) (1) (2) & 2.34 \\
(2) (4) (3) (1) & 2.10 & (4) (3) (2) (1) & 2.09 \\
\hline
\end{tabular}

(2) Theoretical analysis for the optimization of starting sequence of unit

Power wiring diagram of some pumped storage power station shown in Figure 1 is equal to the equivalent impedance circuit shown in Figure 2.

$\mathrm{S}$ represents for equivalent harmonic source of SFC, S1 represents for the electric grid source, $Z_{1}$ represents for the impedance of unit $\# 1$ when it runs as motor, $Z_{2}, Z_{3}$ and $Z_{4}$ represent for the impedance of unit \#2, unit \#3 and unit \#4 when they run as motor, $Z_{5}$ and $Z_{6}$ represent for the load impedance of the auxiliary power system, $Z_{7}$ to $Z_{10}$ represent for the impedance of the main transformer, and the limiting reactors $L_{1}=L_{2}=1.3 \mathrm{mH}$.

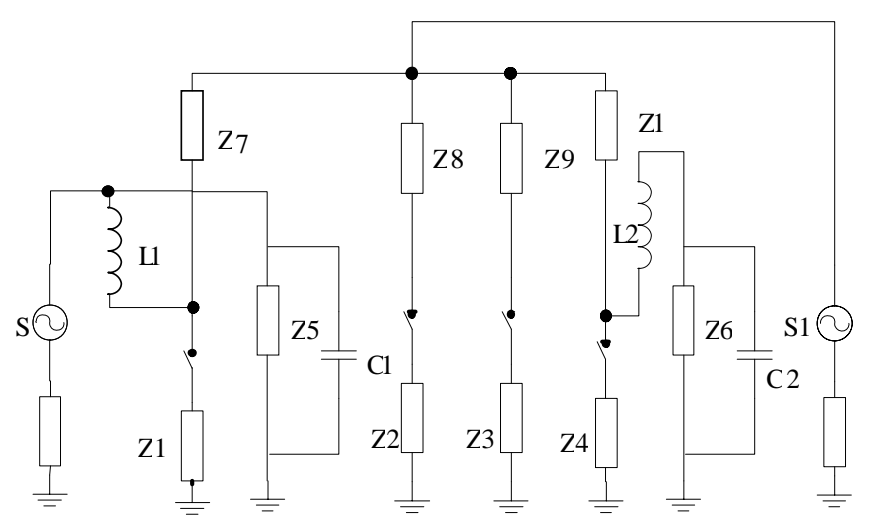

Figure 2. Equivalent impedance circuit of some pumped storage power station

So we can figure out the value of the impedance at the state of fundamental frequency shown as formula (4).

$$
\left\{\begin{array}{l}
Z_{1}=Z_{2}=Z_{3}=Z_{4}=0.783+j 3.42 \\
Z_{5}=Z_{6}=583+j 305 \\
Z_{7}=Z_{8}=Z_{9}=Z_{10}=0.087+j 40.753
\end{array}\right.
$$

Equivalent impedance circuit shown in Figure 2 can be equivalently simplified, and we will get the simplified electric circuit shown in Figure 3. 


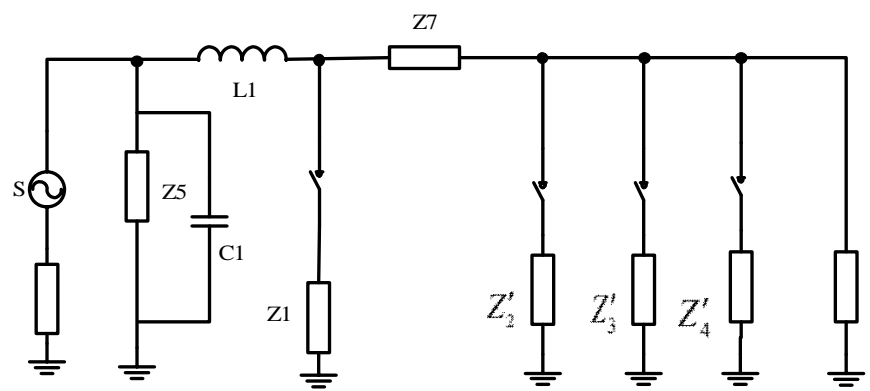

Figure 3.Simplified equivalent impedance circuit

Value of the impedance is shown as formula (5).

$\left\{\begin{array}{l}Z_{1}^{\prime}=0.783+j 3.42 \\ Z_{2}^{\prime}=Z_{3}^{\prime}=Z_{4}^{\prime} \approx 0.87+j 44.182\end{array}\right.$

And we will find that, $Z_{1}^{\prime}<Z_{2}^{\prime}=Z_{3}^{\prime}=Z_{4}^{\prime}$. When $Z_{1}^{\prime}$ was input into the power system, the impedance of the auxiliary power system is much smaller than inputting $Z_{2}^{\prime}, Z_{3}^{\prime}$ or $Z_{4}^{\prime}$ into the power system, thus resulting in much greater harmonic current which means much higher THD of the auxiliary power system. That's to say, if we start other unit after unit \#1 has started and run as a motor, THD of the auxiliary power system will be much greater. Therefore, if we want to get the optical starting sequence of unit, unit \#1 should be started last.

Integrating the results of simulation and theoretical analysis, we can draw conclusions as the following : when we design the starting sequence of unit, if SFC equipment gets its power supply from the $1^{\text {st }}$ main transformer, then start unit \#1 the last; if SFC equipment gets its power supply from the $4^{\text {th }}$ main transformer, then start unit \#4 the last.

\section{Optimization Mathematical Model based on the Motor Power and Auxiliary Power System when starting the motor}

Based on the foregoing analysis, this paper will give the targeted optimization mathematical model of the pumped storage power station as follows.

As shown in figure 1, the terminal SFC gets its power is numbered $i$, the units is numbered $j$, the terminal the $1^{\text {st }}$ auxiliary transformer gets its power is numbered $\mathrm{k}$, the terminal the $2^{\text {nd }}$ auxiliary transformer gets its power is numbered $s$, and we can get the restrictions as formula(6).

$$
\left\{\begin{array}{l}
i=1,4 \\
j=1,2,3,4 \\
s=1,3 \\
k=5-s
\end{array}\right.
$$

SFC gets its drag power from the $1^{\text {st }}$ and $4^{\text {th }}$ main transformers. We have 4 units, numbered $1,2,3,4$. And the $1^{\text {st }}$ auxiliary transformer gets its power from the $1^{\text {st }}$ and $3^{\text {rd }}$ main transformers. And the $2^{\text {nd }}$ auxiliary transformer is restricted by the $1^{\text {st }}$ auxiliary transformer, if the $1^{\text {st }}$ auxiliary transformer gets its power from the $1^{\text {st }}$ main transformer, then the $2^{\text {nd }}$ auxiliary transformer gets its power from the $4^{\text {th }}$ main transformer, if the $1^{\text {st }}$ auxiliary transformer gets its power from the $3^{\text {rd }}$ main transformer, then the $2^{\text {nd }}$ auxiliary transformer gets its power from the $2^{\text {nd }}$ main transformer.

Besides, we set SFC as $S F C_{i j}$, i represents for the terminal SFC gets its power, $\mathrm{j}$ represents for the number of the unit SFC is going to start. $S T_{1 k}$ represents for the $1^{\text {st }}$ auxiliary transformer, $S T_{2 s}$ represents for the $2^{\text {nd }}$ auxiliary transformer. $U_{j}$ represents for the unit going to be started, $U_{m}$ represents for the unit starts the last, and $\{m\} \subset\{j\}$. The optical starting scheme is set to be QD. Then we will get the Optimization Mathematical Model shown in formula (7). 


$$
\left\{\begin{array}{l}
Q D=S F C_{i j} \& S T_{1 k} \& S T_{2 s} \& U_{j} ; \\
k \neq i, s \neq i \\
U_{m}, m=i
\end{array}\right.
$$

The optimization is the coordination of SFC equipment, the auxiliary transformer and the units. The auxiliary transformers and the SFC equipment get their power from the different main transformers, and the corresponding unit of the terminal from which SFC gets its drag power should be started lastly.

\section{Conclusions}

The optimization mathematical model is built which can be generally applied. When optimizing the motor power and the auxiliary power system, avoid SFC equipment and the auxiliary power system getting their power from the same main transformer. Besides, the corresponding unit of the terminal from which SFC gets its drag power should be started lastly. On the other hand, this paper set the power quality as the indicators which is relatively simple and built a set of complete assessment program.

\section{Acknowledgements}

This work was financially supported by Scientific and Technological Project of State Grid Xinyuan Company Ltd (5257001400S9).

\section{References}

[1] Chen Yong, Su Zhaojing. The auxiliary power system design of Qingyuan pumped storage power station. Water Resources and Hydropower, 2012, 5:64-66.

[2] Wei Qiulai. Parameters selection of turbine type for Bailianhe pumped storage power station. Central China Electric Power, 2004, 4(17):53-54.

[3] Ke Zhijian. Safe operation of the auxiliary power system of some pumped storage power station. Water Conservancy \& Electric Power Machinery, 2013, 35(11):87-89. 